\title{
级诰 \\ Assessing the Surface Distortion of Plaster Molds Made with the Use of SLA Models
}

\author{
A.A. Shumkov *, T.R. Ablyaz, K.R. Muratov \\ Materials, Technology and Designing Machines Department, \\ Perm National Research Polytechnic University, 29, Komsomolsky Ave., Perm, Russia \\ *Corresponding author. E-mail address: d-song-ru@mail.ru
}

Received 16.11.2016; accepted in revised form 01.04.2017

\begin{abstract}
The method of determining the accuracy of polymer molds in plaster forms has been discussed. Distortion of the surface of molds and plaster molds has been assessed. It has been found that the presence of monolithic and porous structure in the samples does not change the accuracy of the surfaces when forms are prepared for removing the material of the model. It has been found that in case of full-mold casting it is more expedient to form the mold cavity with cellular adjustable structures of molding prototypes.
\end{abstract}

Keywords: Stereolithography, Photopolymer, Form accuracy, Cell structure, Molding model, Plaster form, Full-mold casting

\section{Introduction}

Currently, the technology of Rapid Prototyping is used for improving the efficiency of foundry production. Key advantage of the RP technology is reduced manufacturing cycle of functional parts, prototypes, tooling and other applications. Today, stereolithography (SLA) is one of the most promising RP technologies. Prototypes made with the use of SLA technology from photosensitive acrylic and epoxy resins are used as thermosetting one-off models in full-mold casting (smelt casting). Compared to the traditional wax models, it allows to reduce the casting cycle several times, to cut down pattern equipment production and development cost. Along with the advantages of using SLA models in casting, there are some limitations. The material used in the process of building a molded model is thermosetting, it is removed from the ceramic shell by burning off. The removal process is accompanied by increased temperature, thermal expansion and deformation between the molding model and the ceramic shell mold (CSM). The difference between the thermal expansion coefficients of the used materials results in mold cracking and defective casts. To reduce this defect,
SLA models with adjustable internal porosity are used. The molding model is a shell with an inner frame made of a set of elementary unit cells. The style of building QuickCast molding burn-off forms has been developed by the 3D System. Square, triangular, hexagonal and octagonal shapes are used for the cells. The presence of the internal structure in the model ensures required rigidity in the process of applying the ceramic shell. When the model material is removed from the CSM, the internal frame is deformed to the inside of the model without destroying the shell.

The analysis of papers $[1,2,3,4]$ has shown that the use of models with inner porosity reduces the contact stresses during the high-temperature removal of the model material from the CSM. The research is aimed at avoiding CSM cracks. Contact stresses are reduced by means of optimum geometric shapes, cell size and the temperature of burning off.

The use of acrylic and epoxy resins for building SLA models imposes limitations on the dimensional accuracy of the castings. The process of building models is accompanied by the layer-bylayer transformation of the polymeric mass from the liquid to the solid state. Volumetric changes cause material shrinkage and shell warping due to the residual internal stresses. The internal structure 
in the form of the frame partially compensates for the warping of the molding model.

The analysis of works $[5,6,7]$ has shown that the accuracy of the SLA models is most affected by positioning, thickness of the layer, type of post-processing, and by the prototypes design features. When the critical parts of the model are positioned at the angle of 45 degrees, and thickness of the build layer is reduced, the form error decreases, and the quality of the surface improves.

The accuracy of a mold made by burn-off SLA models has not been fully studied. The actual problem is determining the accuracy of the inner cavity of the obtained CSM.

The study is aimed at studying the accuracy of the surface of a mold made by an SLA - burn-off model.

\section{Materials and methods of study}

A mask SLA from the Envisiontec Company was used for making cast burn-off models. The principle of action is shown in (Fig. 1).

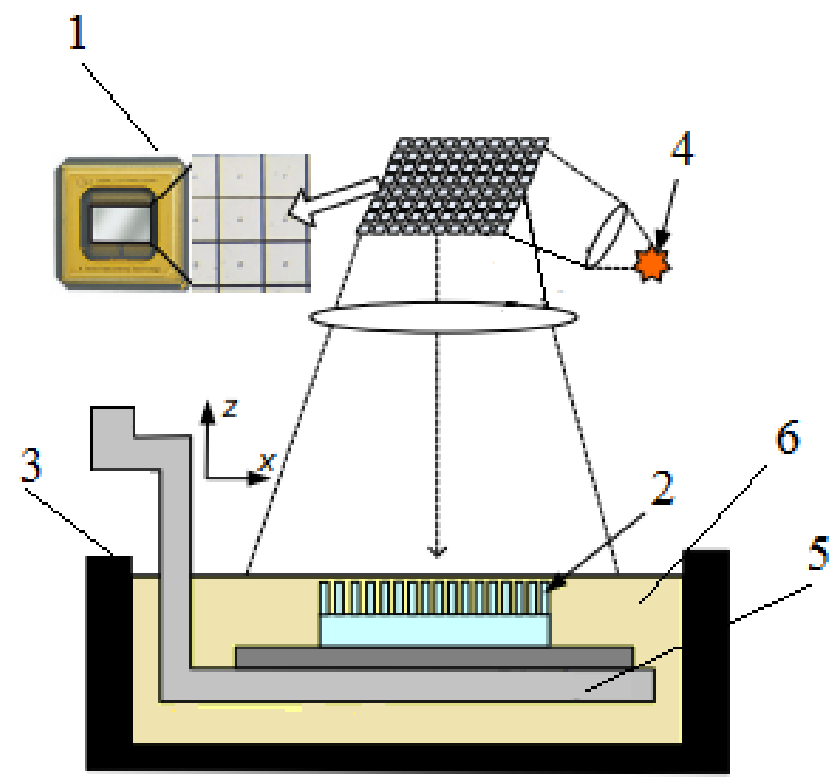

Fig. 1. The operating diagram of an SLA installation with the use of the DLP technology: 1 - the digital micromirror device

(DMD); 2 - the prototype; 3 - the reservoir; 4 - the light source; 5 - the platform; 6 -the liquid photopolymer

The essence of the technology is in layered building of a computer CAD model, creating a mask of each layer's image on the working platform 5 of installation. As the layer cures under the action of ultraviolet light source 4 , the height of the working platform is decreased by the thickness of the next layer, and the process is repeated. The main difference from the classical stereolithography is the action of the ultraviolet radiation on the processed layer of the photosensitive material. The advantages of this method are the speed of building, and the accuracy of the polymer prototypes.
For assessing the distortion of a plaster mold surface, molding models with various internal structures have been made. Modes of the models building process are shown in Table 1.

Table 1

The mode of the process of building on the Envisiontec Perfactory Xede stereolithographic installation

\begin{tabular}{ccc}
\hline Thickness of the layer & $\mathrm{mm}$ & 0.05 \\
\hline $\begin{array}{c}\text { Thickness of the } \\
\text { supports }\end{array}$ & $\mathrm{mm}$ & 0.280 \\
\hline Height of the supports & $\mathrm{mm}$ & 3 \\
\hline $\begin{array}{c}\text { Time of the model cross } \\
\text { sections exposure }\end{array}$ & $\mathrm{sec}$ & 6.5 \\
\hline $\begin{array}{c}\text { Time of supports } \\
\text { exposure }\end{array}$ & $\mathrm{sec}$ & 13 \\
\hline
\end{tabular}

The samples have been made as cubes with side size $30 * 30 * 30$. The structural design of the samples is shown in Fig. 2.

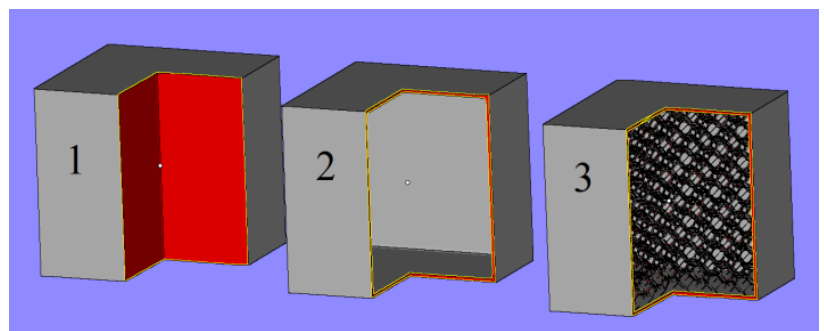

Fig. 2. Manufactures samples : 1 - a sample with monolithic structure; 2 - a sample with hollow structure, wall thickness is 0.5 $\mathrm{mm} ; 3$ - a sample with an internal cellular structure that consists of Wigner - Seitz elementary cells, shell thickness is $0.5 \mathrm{~mm}$, cell size is $5 \mathrm{~mm}$, thickness of cell lintel is $0.5 \mathrm{~mm}$

After extraction, the grown samples were rinsed in alcohol to wash out the remaining photopolymer material and postprocessing materials due to the exposure to radiation from fluorescent lamps, to increase strength in creating plaster molds. For the purpose of comparing the accuracy of the casting models and reproducibility of their profile in a plaster form, their surfaces were measured.

The stages of preparing a plaster form for assessing reproducibility of molding models' surfaces accuracy is shown in Fig. 3.

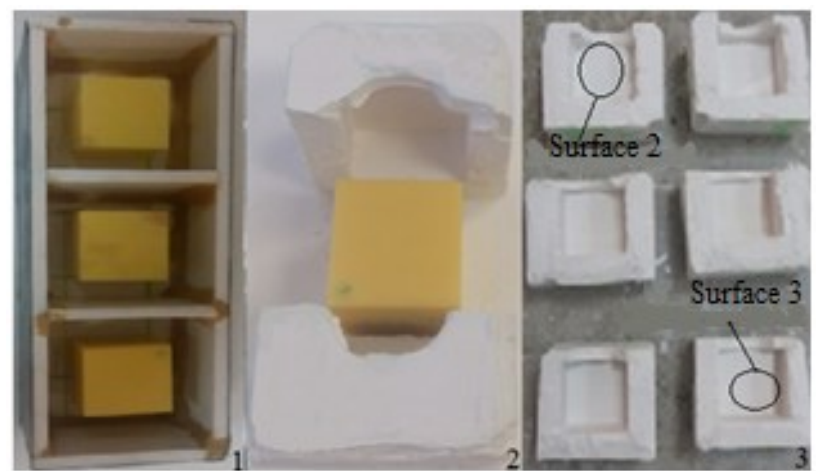

Fig. 3. The stages of preparing a plaster mold for measuring 
In stage 1 (Fig. 3.), the molding models are placed in a box for pouring a thinly fluid plaster mixture. After the plaster forms cure, the molding models were extracted at stage 2 (Fig. 3.). In phase 3 (Fig. 3.), the halves of the molds are shown prepared for measuring accuracy of the molding surfaces of the models [8]. The accuracy of plaster molds measurement is shown in Fig. 4.

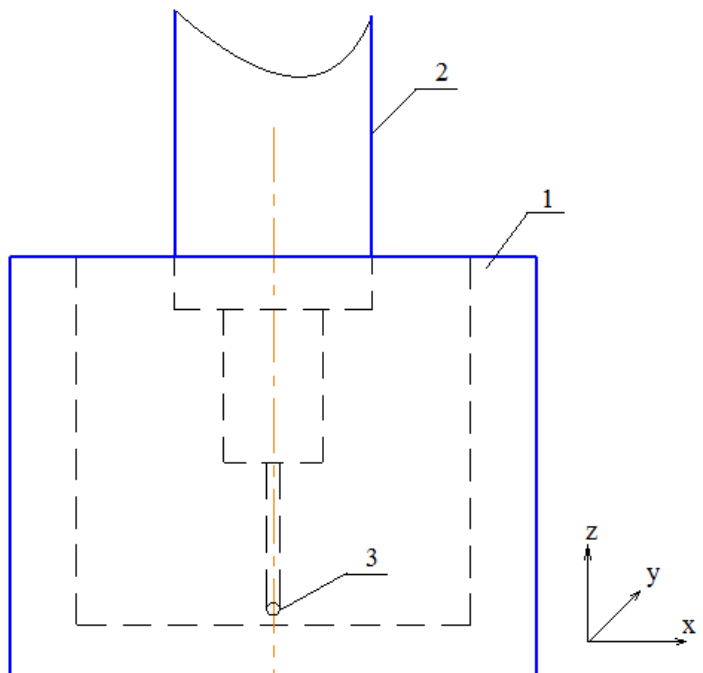

Fig. 4. The layout of measuring plaster molds surface accuracy with SLA models: 1 - the plaster molding form; 2 - the measuring head; 3 - the probe indicator.

The plaster form is set on the work table of a three-coordinate measuring machine. 10 points along the $y$-axis are taken from the vertical surfaces 2 and 3 of form. The coordinates of each point are a set of values: $\mathrm{x}$ is the auxiliary coordinate, which remains virtually unchanged, $\mathrm{y}$ is the probe movement along the axis, and $\mathrm{z}$ is surface deviation $[9,10]$.

\section{Results and discussion}

The data obtained after measuring the surface of 2 molding models and plaster molds is shown in Fig. 5.

Fig. 5 - 6 show that the use of SLA models at the stage of forming the internal cavity of a plaster mold to be filled with metal repeats exactly the profile of the model profile.

The most accurate repeatability of the profile of molding models in plaster molds was shown by samples with monolithic and cellular adjustable structure. However, the use of molding models with monolithic structure made of acrylic photopolymer material results in defects of the molds under the high temperature during material extraction. It is advisable to use designs with controlled internal structure, which folds to the inside when the temperature is increased, without destroying the molding form.

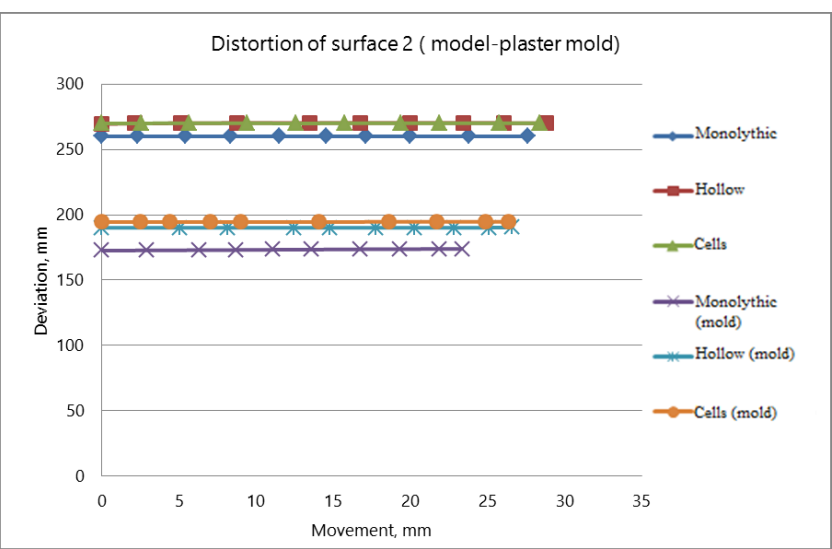

Fig. 5. Distortion of the surface 2 of a plaster mold in contact with an SLA model

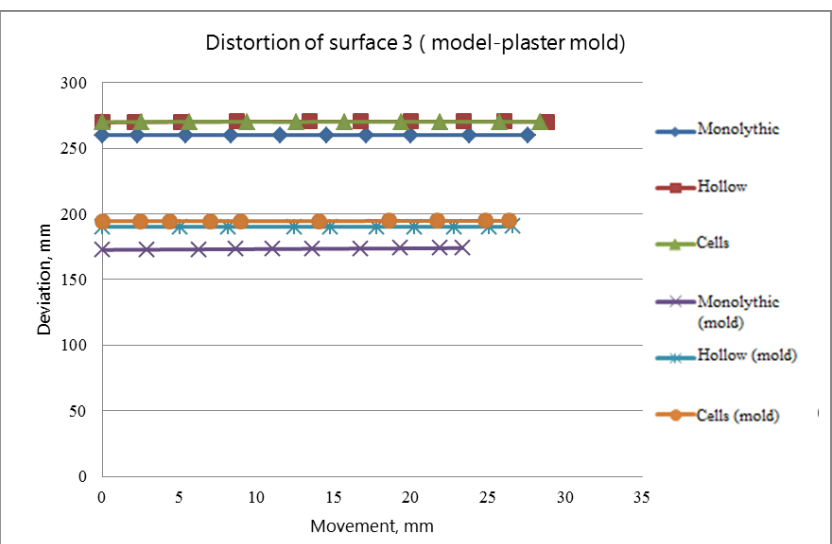

Fig. 6. Distortion of the surface 3 of a plaster mold in contact with an SLA model

\section{Conclusions}

1. Applicability of molding models made with the use of stereolithography for forming the inner cavity of the molding form has been experimentally established.

2. In order to ensure form accuracy at the stage of preparation and further use, it is advisable to make models with internal adjustable structure that consists of a set of Wigner - Seitz cells with the dimensions of $5 \mathrm{~mm}$ and lintel thickness of $0.5 \mathrm{~mm}$.

\section{References}

[1] Hague, R., D’Costa, G. \& Dickens, P.M. (2001). Structural Design and Resin Drainage Characteristics of QuickCast 2.0. Rapid Prototyping Journal. 7(2), 66-72.

[2] Pandey, P.M., Reddy, N.V. \& Dhande, S.G. (2004). Part Deposition Orientation Studies in Layered Manufacturing. In the Proceeding of International Conference on Advanced Manufacturing Technology, (pp. 907-912). 
[3] Yao, W.L. \& Leu, M.C. (2000). Analysis and Design of Internal Web Structure of Laser Stereolithography Patterns for Investment Casting. Materials and Design. 21(20), 101109.

[4] Norouzi, Y. \& Rehmati, S. (2009). A Novel Lattice Structure for SL Investment Casting Patterns. Rapid Prototyping Journal. 4(14), 255-263.

[5] Kang, H.-W., Park J.H. \& Cho, D.-W. (2012). A Pixel Based Solidification Model for Projection Based Stereolithography Technology. Sensors and Actuators. A 178, 223-229.

[6] Pandey, P.M., N.V. Reddy and S.G. Dhande, 2004. Part Deposition Orientation Studies in Layered Manufacturing. In the Proceeding of International Conference on Advanced Manufacturing Technology, (pp. 907-912).
[7] Zhou, C., Chen, Y. \& Waltz, R.A. (2009). Optimized Mask Image Projection for Solid Freeform Fabrication. ASME Journal of Manufacturing Science and Engineering. 1s31(6), 1-19.

[8] Pastirčák, R., Sládek, A. \& Kucharčíková, E. (2015). The Production of Plaster Molds with Patternless Process Technology. Archives of Foundry Engineering. 15(2), 91-94.

[9] Budzik, G., Marciniec, A., Markowski, T., Oleksy, M. Cygnar, M. (2009). The Geometrical Precision of the Silicone Matrices to the Manufacturing of the Models of the Gear. Archives of Foundry Engineering. 9(2), 137-142.

[10] Budzik, G. \& Matysiak, H. (2010). Geometric Accuracy of Wax Bade Models Manufactured in Silicon Moulds. Archives of Foundry Engineering. 10(1), 399-404. 